\title{
What remains of History? \\ Historical epistemology and historical understanding in Scotland's Curriculum for Excellence
}

Joseph Smith 


\begin{abstract}
This paper critically examines the framing of historical knowledge in the primary and 'broad general education' phases (ages 4-14) of Scotland's Curriculum for Excellence. The paper focuses on curriculum documentation, particularly the curriculum's aims and 'Experiences and Outcomes and evaluates these in light of recent research on children's historical understanding. It is argued that the decision to frame historical understanding as 'People, Past Events and Societies' within the context of a 'social studies' curriculum area has been motivated by a misunderstanding of history's unique disciplinary identity. It is argued that history curricula must take account of the unique ontological and epistemological challenges posed by investigating the past and that by failing to do this, 'Curriculum for Excellence' offers children in Scotland a problematic representation of what it means to study the past.

The paper challenges the curriculum in both epistemic and pedagogical terms, before suggesting that a rigorous study of history as a discipline can make a valuable contribution to children's personal and social development.
\end{abstract}

\title{
Keywords:
}

History; Curriculum for Excellence; Social Studies; progression; historical understanding; historical epistemology

Scotland's Curriculum for Excellence (CfE) has an ambivalent relationship with the subject of history. While history is recognised as a discrete subject at the so-called 'senior' phase (ages 14-19), students in primary school (4-11) and during the 'broad general education' phase (11-14) of their education are instead offered an 'organiser' known as 'People, Past Events and Societies' (PPES) within a broader 'social studies' course. This decision to avoid the word 'history' in the early phase of high school represents a continuation of the approach taken by the previous version of the Scottish curriculum (Curriculum 5-14) which referred to 'People in the Past' in the context of 'Environmental Studies'.

The reason for these lexical innovations is not entirely clear, but the existence of 'social subjects' or 'social studies' seems designed to encourage, albeit implicitly, the teaching of an integrated approach to History, Geography and Modern Studies. Elsewhere, Curriculum for Excellence explicitly encourages 'greater cross-subject activity' (Scottish Executive, 2004, p. 4) and insists that 'the curriculum should include space for learning beyond subject boundaries, so that children and young people can make connexions between different areas of learning (Scottish Government, 2008 p.21). However, progress towards this aim has been uneven; while effective interdisciplinary projects exist (Fenwick, et al., 2013), most schools have avoided the challenges posed by thorough integration (Priestley, 2009), preferring in most cases to teach discrete subjects, sometimes on a rota basis within a timetabled social subjects slot.

This paper will argue that the inclusion of PPES within a broader 'social studies' curriculum area has been badly conceived. This is not to argue that history ought not, or cannot, be part of an integrated 
social studies curriculum, but that where such an approach is favoured curriculum designers must understand the unique disciplinary contribution that history makes to a child's education. History matters because it transforms a child's perceptions through exposure to the unfamiliar and rigorous engagement with evidence. In CfE, history takes an instrumental role; providing examples for the wider curricular aims of understanding democracy and evaluating sources. CfE understands history's contribution to social subjects dimensionally - the past as shining light on the present.

The tension between two competing imperatives (cross-curricular learning and the disciplinary integrity of history) is not recognised by CfE, with the result that PPES has a split identity - looking inwards towards the other 'social subjects' and outwards towards its progenitor discipline of history. Curriculum for Excellence fails to recognise the profundity of this split and so throws together two contradictory visions of the purpose of school history: as an aid to socialisation and self-actualisation on the one hand, and as an epistemic frame for uncovering and recounting the past on the other. These visions are ontologically mutually exclusive: one prizing historical knowledge for its extrinsic utility, the other a commitment to the pursuit of objectivity. Since CfE fails to ask fundamental questions of the nature and limitations of historical truth, it valorises the subjective truth of identity formation within a notional framework of 'historical understanding' without acknowledging their mutual incompatibility. This paper is best seen, therefore, as a case-study contribution to the debate opened by Priestley and Humes (2010) who accused CfE of being incoherently structured and contain[ing] epistemological and pragmatic contradictions' ( $p 355$ ).

This paper will begin with a summary of the debates over the nature and purpose of history in schools and will pay special attention to the oft-misunderstood 'disciplinary' approach which now dominates in many countries. There will then follow a short account of the introduction of Curriculum for Excellence and the place of historical learning within it. The analysis section of the paper will work at the intersection of these two fields, critically evaluating the model of progression presented by the curriculum in light of current knowledge about how children make sense of the past. It will be argued that the fundamental weakness of the CfE approach is its failure to ask ontological questions about the possibility of historical truth and that other problems are merely a corollary of this original error. Consequently, analysis of the curriculum will take place at three levels: ontological, epistemological and pedagogical. The paper is a critical analysis of policy documents and makes no claims to knowledge about current practice in schools. Inevitably, there is a considerable implementation gap between policy and practice and so we should be careful about inferring that what happens on paper is what happens in the classrooms. But policy does shape the language that is used to talk about practice, it shapes expectations and exercises a powerful influence over resourcing. Therefore, while this paper uses no empirical claims about practice in schools, it does discuss examples where apparently ahistorical practice in schools might be implicitly endorsed.

\section{Purposes of school history}

If, as in Alfred Whitehead's famous aphorism, all philosophy is footnotes to Plato, then all discussion of the purpose of history might be seen as footnotes to Nietzsche. In On the Use and Abuse of History for Life (1874), Nietzsche offers us three motivations for studying the past (each of which he subsequently dismisses). The first is "monumental" history, the use of history to hearten oneself in weaker moments with "the knowledge that [a] great thing existed and was therefore possible, and so may be possible again" (p. 3.2). The second is "antiquarian" which is "necessary to the man of conservative and reverent nature who looks back to the origins of his existence with love and trust". For the antiquarian, the past reveals his identity as though, "the history of the town becomes the history of himself" (p. 4.3). Finally, "critical history" is history written by "he whose heart is oppressed 
by an instant need [for]....the history that judges and condemns" (p. 4.2) Characteristically, Nietzsche's objections to these three schools are moral: he feels that a preoccupation with the past limits the capacity or the will to act. However, without subscribing to a Nietzschean world view, it is still possible to read these as contributions to contemporary debates on the purposes of school history.

Nietzsche's 'monumental history' is analogous to the argument that history provides a store of valuable examples and lessons with which children ought to be familiar. These examples form the shared cultural capital of a society and so aid social cohesion and social mobility (see Hirsch, 1987). Nietzsche's 'antiquarian' history, on the other hand, is related, but contains the additional dimension of internalisation, history aids the formation of the self, the creation of identity (often one informed by nationhood). These ideas are often erroneously associated exclusively with the political right, but such ideas cut across political distinctions. What unites these viewpoints is not politics, but the instrumentalisation of the past. The idea that the past exists in shared stories with self-evident lessons which shape us all and which should, in turn, be used to shape children. This shaping should not necessarily carry overtones of indoctrination, but even in its weakest form - that history should 'fit [children] to be citizens of a liberal-democratic society' (White, 1992, p. 19) - it still underpinned by political and ethical assumptions about the lessons of the past.

Nietzsche's monumental and antiquarian history might be said, therefore, to form the core of the 'traditionalist' defence of a history education ${ }^{1}$ which is often counterposed with a disciplinary (or often simply 'new') approach to the subject. The disciplinary approach is much misunderstood, often being presented as Nietzschean 'critical history' - an attempt to be subversive, contrary or just 'trendy' (see Partington, 1986; Kedourie, 1988; McGovern, 2007). These are, however, fundamental (and possibly wilful) misunderstandings. Instead, as the next section explains, a disciplinary approach to school history is an epistemological - not political - position.

\section{History Education as Disciplinary Knowledge}

Many areas of the world now take a disciplinary approach to the teaching of the past which states simply that children ought to be inducted to history both as a body of knowledge and as a 'way of knowing' (Wineberg, 2001). The fashion in public discourse has been to speak in terms of a 'skillsapproach' in opposition to a 'content approach', but this is an unhelpful framing of the debate in which skills become disembodied ends in themselves rather than the very fabric of the discipline. Instead, history educators prefer the terms substantive knowledge (to know that) and procedural knowledge (to know how) (Lévesque, 2008). This approach - which has its roots in the work of Janet Coltham and John Fines (1971) and the English Schools Council History Project (1976) - has informed curricula across the world; including England (Counsell, 2011), New Zealand (Ormond, 2011) and Canada (Seixas \& Morton, 2013). In each of these countries procedural concepts (such as causation, chronology, change) act as curriculum organisers, aspects of historical knowledge that children can deepen and develop. This does not mean that substantive knowledge has diminished status in these curricula each country still details events that it deems significant - but there is a shared recognition that substantive knowledge on its own provides no scope for progression. Since it is not inherently more challenging to understand one event than another, school curricula must be based on 'progression' in

\footnotetext{
${ }^{1}$ The seemingly neutral traditionalist appeal for 'history for its own sake' was famously skewered by John Slater who asked simply "who is the 'it' on whose behalf history is learnt? Someone other than the learner or the historian? Clio perhaps? Alas, she does not exist" (1992b, p. 47).
} 
procedural knowledge rather than substantive. Counsell (2011) makes this point when she describes procedural concepts as 'the most efficient device we have for defining the structure of the discipline in curricular terms' (p. 217).

The ubiquity of this approach is not the result of pedagogical fashion or of producer capture, but is instead an inevitable consequence of ontological questions at the heart of history. A history curriculum can never ask children simply 'to learn what happened' for at least two reasons: because not everything that happened can be learnt, and because agreement on what happened is not guaranteed (Lee, 1991, p. 40). Consequently, a traditional narrative approach to the subject is unsatisfying. Equally unsatisfying, however, is a relativist approach to the subject which has no faith in 'truth' or 'objectivity'; just because an infinite number of accounts are possible, this must not mean that all accounts are equally valid. Once these unhappy ontological poles are accepted, the historical discipline becomes - for pupils as much as professional historians - a question of how to assess the validity of accounts and of how to form more valid accounts. Thus, as Evans (1999) argues, while 'objectivity' might be an ontologically impossible aspiration, it remains very satisfactory guiding principles for the discipline. This is not the same as the naïve Rankean injunction to 'tell it how it was' but a more modest faith that the historical method is the best tool currently available for investigating what happened in the past.

Once this ontological reasoning is accepted, 'learning about the past means learning about the discipline too' (Lee, 1991, p. 44). Procedural concepts emerge because 'historians often share a large measure of agreement about what questions are worth asking at any particular moment, because they share explanatory ideas which change rather slowly' (p45). Lee's views here are prefiguring the social realist turn in the sociology of education, which argues that legitimate knowledge is determined by codes of association which are "enshrined in institutions such as university subject departments... specialist academic organisations... and school subject associations" (Young, 2008a, p. 32). Thus, the disciplinary approach to school history is best understood in social realist terms wherein procedural concepts give credibility and legitimacy to certain kinds of historical enquiry. For example, the questions 'Why did World War One occur?' and 'How did democracy develop in Britain?' have more conceptual value (in terms of causation and change, respectively) than, say, 'How many soldiers fought at Rorke's Drift?' This is not to say that history in schools and history in academia should be indistinguishable - plainly this would be absurd - it is merely to state that history in schools must have a disciplinary dimension. As Lee writes,

'The ability to recall accounts without any understanding of the problems involved in constructing them or the criteria in evaluating them has nothing historical about it. Without an understanding of what makes an account historical, there is nothing to distinguish it from the ability to recite sagas, legends, myths or poems' (Lee, 1991, pp. 48-49).

This definition of historical knowledge in disciplinary terms has had a number of positive implications for teachers of history. Perhaps most importantly, it has afforded a compelling justification for history's place in the school curriculum (Lee, 1991; 1992). The school curriculum is a fiercely politicised arena in which special interest groups compete to have their voices included (Foster \& Crawford, 2006; Taylor \& Guyver, 2011). Arguably, a disciplinary/ social realist conception of the subject provides a way of depoliticising history's place in the curriculum. The recent debate over the National Curriculum in England has shown how a disciplinary defence of the subject has enabled history teachers to resist politically-motivated selection of content (Smith, 2015). In the words of Counsell disciplinary knowledge is the 'best hope we have of dealing with the problem of the canon' since it teaches 'the 
processes of knowledge construction [so that] pupils can challenge the canon itself' $(2011$, p. 218). This does not mean that the question of selection of content is somehow divorced from questions of power, but it does provide a framework wherein common sense assumptions that a particular event is 'significant' or 'worthy of study' are subjected to critical examination.

The second gain from a social realist conception of the subject is the way in which it has provided a framework in which to analyse children's historical understanding: it is clear that many children find history difficult, but it is only when we are absolutely clear what 'history' expects of children that we can begin to explain this difficulty. The work of Denis Shemilt (1983) and Project CHATA (Lee \& Ashby, 2000) amongst others have allowed historians to see difficulties in children's thinking, but also establish a hierarchy of historical understanding which points to something more than mere Piagetian maturation. This research has therefore allowed history teachers to ask the educationally vital question 'What does it mean to get better at history?' Crucially, such research has been epistemologically inductive - analysing children's explanations for the past, rather than attempting to scaffold these. Inevitably, such research has not always survived contact with designers of national curricula who - driven by demands for assessment models - favour objectives or statements of competence. Consequently, in many countries, these broad statements about 'what it means to get better at history' have regrettably morphed into endlessly subdivided levels of competence.

We turn now to the specific case of the status of historical education in Scotland's Curriculum for Excellence. In their analysis of the curriculum as a whole, Priestley and Humes (2010) argue that 'there is hardly any mention of the big philosophical and sociological questions which... are necessary precursor to planning a curriculum' (p. 354). It will be argued that what is true at the overarching curriculum level is also true at the level of individual subjects.

\section{The place of 'History' in Scottish education}

In Scotland, the question of whether the 'social subjects' should be integrated or taught as discrete subjects has a long history (McGonigle, 1999). In general, these debates have generated more heat than light and have invariably resulted in compromise - a recognition that 'social subjects' have much in common, but a simultaneous recognition of their distinctive identity. It was only in the late 1980s as a National Curriculum was proposed in England, that Scotland produced a national framework of practice. Curriculum 5-14, as it became known, was implemented between 1991 and 1993. Setting a precedent that would be repeated in Curriculum for Excellence, history had no distinctive identity; instead it was to be taught as an aspect of 'Environmental Studies' (SOED, 1993).

Devolution provided a natural opportunity for Scotland to review its approach to the curriculum. Beginning with a discussion paper in 2004, Curriculum for Excellence was conceived at a time when interdisciplinary approaches to learning were growing in popularity worldwide. The popularity of these approaches can be attributed to economic imperatives - a growing demand that children should be prepared to be the workers of the twenty-first century (Young, 2008b) (Young \& Muller, 2010). This transnational agenda, together with Scotland's existing practice of teaching 'environmental studies', made it likely that history would not feature as a distinct subject in the new curriculum. This suspicion was reinforced when, in 2005, the then Scottish education minister, Peter Peacock, said of history "perhaps we will not be teaching it in the same way in a timetabled slot marked history, but as a contributor to broader forms of learning" (Munro, 2005). This prompted an inevitable backlash from those who sought to defend the subject's place and led to a retraction in which Peacock clarified that he 'was quite clear that history, as a distinct discipline, has a hugely important role to play' (cited in (Henry, 2006, p. 34)). 
The question of exactly what this 'hugely important role' was has never been satisfactorily answered. When it seemed that history as a subject would be under threat the Scottish Association of History Teachers (SATH) issued a statement which asserts the subject's worth in socio-cultural rather than disciplinary terms:

\begin{abstract}
"Let me say, unequivocally and unashamedly, that SATH will continue to advocate the central importance of history in the curriculum, not because we refuse to be outward looking or innovative in developing the curriculum, but because we believe that as Scotland develops as a country with its own Parliament in the twenty-first century, it is essential that its young people have a sense of their heritage and identity" (Henry, 2006, p. 35)
\end{abstract}

In this way, history's importance was asserted, but unhistorical concepts such as 'heritage' and 'identity' were foregrounded. This defence of history - valuable and passionate though it is - misses an opportunity to assert history's disciplinary uniqueness. Echoing Lee (1992), it could be suggested that although Henry provides a compelling reason for students to learn about Scotland's past, there is no explicit reason given why this should be studied through a school subject called history.

In fact, the absence of the word 'history' became something of leitmotif as curriculum development progressed. A Curriculum for Excellence: Progress and Proposals (Scottish Government, 2006a) retained the label of 'social studies' from Curriculum 5-14 and spoke of 'learning in historical... contexts' within that (p. 14). Later in the same year Building the Curriculum 1(Scottish Government, 2006b), labelled this strand 'People in the Past' (a further borrowing from Curriculum 5-14) which later became 'People, Past events and societies' in Curriculum for Excellence: Experiences and Outcomes (Learning and Teaching Scotland, 2008). Peter Hillis spoke for many history teachers when he complained, 'it is disappointing that curriculum planners persist with "education speak" which refuses to use the word History' (Hillis, 2008, p. 497).

However, the absence of the word history meant more than simple rebranding, as the expectation of interdisciplinary learning in social studies remained. Referring to the three 'organisers', of which PPES was one, Experiences and Outcomes asserted they 'recognise the special contribution made by each of the social subjects' but also 'provide children and young people with opportunities for effective interdisciplinary working by making connections across and between subject boundaries' (Learning and Teaching Scotland, 2008, p. 279). However, the purposes of 'social studies' are treated holistically and the 'special contribution' of 'People, Past Events and Societies' is never developed. Of the ten broad aims identified for social studies, PPES contributes to the first six. These are

1. develop my understanding of the history, heritage and culture of Scotland, and an appreciation of my local and national heritage within the world

2. broaden my understanding of the world by learning about human activities and achievements in the past and present

3. develop my understanding of my own values, beliefs and cultures and those of others

4. develop my understanding of the principles of democracy and citizenship through experience of critical and independent thinking

5. explore and evaluate different types of sources and evidence

6. learn how to locate, explore and link periods, people and events in time and place

Of these, only aim 6 is distinctively historical, the others take a broad area of study; human achievement, say, and ask students to broaden their understanding through a range of dimensions, for example, past and present, time and place.

Somewhat intriguingly, Education Scotland (the successor to Learning and Teaching Scotland) released further guidance on assessment in 2013 which complicated the picture further by identifying 
'significant aspects of learning' (Education Scotland, 2013). Although this document stated the significant aspects of learning in the social studies were 'derived from the rationale in the principles and practice paper', there was a noticeable shift to a more disciplinary way of thinking. For example, students were now expected to become 'aware of change, cause and effect, sequence and chronology' and the word 'maps' appeared for the first time. Although these changes are welcome from a disciplinary perspective, it is not clear how the differing emphases between the Experiences and Outcomes and the Significant Aspects of Learning are to be reconciled.

\section{Analysis}

Having traced the origins of 'People, past events and societies' in Curriculum for Excellence and also adumbrated the disciplinary approach to history teaching, I turn now to a comparison between the two. In certain key respects, as will be seen, CfE borrows heavily from the disciplinary tradition, but it does so in ways that are educationally unsatisfying. This analysis will look first at the problematic ontology which underpins the study of the past in CfE, before showing how these initial errors contribute to less significant (though more numerous) epistemic and pedagogical ones.

Furthermore, it will be shown that where attention is paid to the disciplinary nature of the subject, there is limited and confused understanding of what constitutes progression in children's understanding of the past. In this respect, the paper supports Priestley and Humes' (2010) partiallysubstantiated contention that 'there are multiple instances where progression and/or continuity between levels is haphazard (p. 357).

\section{Ontological Errors}

Clearly, historical ontology is an enormously complex field: since the past has no tangible existence it is uncontroversial to argue that accounts of the past are constructs of those who write them. However, historians working in the western tradition argue that methodological rigour can allow them to construct better quality accounts of the past. These accounts seek to make their truth claims accountable to the reader through the architecture of footnotes and authorial honesty - in this way, historians operate as community of practice committed to the pursuit of truth, while accepting that they too, are part of the historical process. Such a compromise has not been enough to assuage the ontological doubts of committed post-modernists, among them Keith Jenkins (1991), for whom these 'rules of verification' are little more than a Barthesian 'reality effect'.

However, history is not as blindly positivist as some of its critics imply. The purpose of history is not the pursuit of a single all-encompassing grand-narrative, but the more modest acceptance that the past is in some sense knowable to the extent that it is possible to judge the quality or accuracy of a given account of the past. Potter and Lopez's summary of critical realism in social science has a neat parallel in the historian's ambitions,

\footnotetext{
"The production of knowledge is a social process... However knowledge cannot be reduced to its sociological determinants of production. Truth is relative, to be sure, but there is still both truth and error (as well as lies!)' (2001, p. 9).
}

To history teachers of a disciplinary persuasion, schooling children in the historical method does not represent a faith that the historical method is infallible; quite the opposite, it is precisely because our knowledge of the past is partial, nuanced and contingent that we must understand the processes through which historical accounts are constructed. Nevertheless, to study history is to take an ethical position: in Lee's words, "commitment to truth, respect for the past... and impartiality are built into learning history" (1991, p. 51). 
In Curriculum for Excellence, we see the potential pitfalls of abandoning this ethical starting point the danger that the past might be plundered and instrumentalised in ways that are not historically valid which then, in turn, leads to problems conceptualising and teaching the past.

Consider the following expectation of progression for students:

\begin{tabular}{|l|l|}
\hline Third & $\begin{array}{l}\text { I can make links between my current and previous studies, and show my understanding } \\
\text { of how people and events have contributed to the development of the Scottish nation. } \\
\text { SOC 3-02a }\end{array}$ \\
\hline Fourth & $\begin{array}{l}\text { I have developed a sense of my heritage and identity as a British, European or global citizen } \\
\text { and can present arguments about the importance of respecting the heritage and identity } \\
\text { of others. SOC 4-02a }\end{array}$ \\
\hline
\end{tabular}

Firstly, it is immediately obvious that the fourth level does not constitute a progression of the third. The third level has a clear conceptual focus - encouraging children to study development over time, what might conceptually be called historical change. The outcome might be criticised by some for its nationalist scope, but it is, nonetheless, what one might consider a legitimate historical enquiry. However, it is not at all clear how or why the fourth level might be considered an extension of the third. The immediate answer is dimensional - the broadening of scope (from Scotland at the third level to British, European and Global) in the fourth - but a closer analysis shows why this 'progression' is inadequate.

At the fourth level (though not at the third) the problematic term 'heritage' is introduced. In everyday use, heritage and history may be considered linked, but any notion of heritage is necessarily antagonistic to the historical method. David Lowenthal (1997) has been at the forefront of theorising this distinction, where 'heritage' makes a 'weapon' of history. It uses the past to support or oppose interests in the present and is not subject to critique but is held as 'a dogma of roots and origins which must be accepted on faith' (p. 2). Heritage might be defined as the inherited culture of previous generations, and culture is no respecter of evidence.

The specific case of Scottish identity has been given particularly acerbic deconstruction by Hugh Trevor-Roper $(1983,2008)$ who assembles arguments made earlier by Hay and Telfer Dunbar, to argue that many of the apparent shibboleths of 'traditional' Scottish culture - such as the kilt and the bagpipes - were nineteenth century appropriations. These cultural manifestations are of interest to a historian; telling, as they do, the story of how a distinctive Scottish culture was reasserted in the century after the Union of the Crowns. Although it is perfectly possible to teach the historical construction of these 'ancient' traditions - and schools no doubt already do this - by using the terms 'heritage' and 'identity', the curriculum allows pupils to emphasise tradition over the rigour of the historical method. No doubt it could be argued that this is a 'social studies' curriculum and not a history curriculum - but these two subjects have very different aims. One aims to make sense of the society to which the pupil belongs, the other to ask question about how we can know about the past. In one arena, tradition, myth and heritage are essential content; in the other, they are problematic narratives. In the words of Peter Lee, "Handing on a common heritage is nothing to do with learning history... This kind of practical past is not necessarily illegitimate, but it is not to be confused with history" (1991, p. 41).

Significantly, 4-02a not only expects children to develop their own identity, but also to 'present arguments about the importance of respecting the heritage and identity of others'. This poses the question of whether another's sense of 'heritage' or 'identity' should be respected uncritically or whether they should be subject to historical scrutiny? John Slater is characteristically nuanced on this point: history 'not only helps us to understand the identities of our communities, cultures, nations by 
knowing something of the past, but also enables our loyalties to them to be moderated by informed and responsible scepticism' $(1989$, p. 16). Although a sense of identity is an important outcome of a historical education, it must not be divorced from the falsifiability tests to which all historical narratives are subject.

It is important to respect others' identities as CfE reminds us, but it is equally - perhaps more important to respect evidence and to challenge those identities (including one's own) which are based on historical falsehoods. Do we wish children to respect the identity of a racist and his distorted sense of heritage? We would hope not, but if a commitment to historical accuracy is not central to an historical education, then one wonders where the tools will be found to counter him. By including this outcome, CfE veers dangerously close to a kind of relativism based on a misreading of historical ontology wherein the accepted fact that no account can be 'the truth' is distorted to reward accounts for the extent to which they are 'true to the pupil', rather than for their ability to withstand scrutiny. Priestley and Humes' (2010) criticised the phrasing of the Es and Os as 'I can' statements by writing 'the subjectivity of the experiences is misleading, an artifice devised by the planners rather than a true reflection of the learning process' (p.353). However, in the specific case of 'identity' the subjectivity is real and disturbingly so. This is not to say that the subjective or personal has no place in a historical education. History must emphasise the present as product of the past, the individual as both antecedent and change agent, lest it become in Slater's words 'a humanity dehumanised' (Slater, p. 13). However, while the history teacher cannot and should not 'sculpt' a child's identity, they are responsible for providing the tools of coherence, plausibility and empathy which the child might use.

Unfortunately, empathy, too, is a problematic concept in Curriculum for Excellence. A very specific kind of empathy has to be at the heart of all historical thinking - it is the empathy which comprehends the world view of the historical actor and contextualises his/her actions within that world view. This is, before all else, a historical endeavour and differs markedly from 'empathy' as commonly understood. While both forms of empathy try to see the world from another's point of view, historical empathy is complicated beyond all recognition by the strangeness of the past. For this reason, historians have tried scrupulously to avoid the word, Collingwood (1946) developed the common idea of a 'historical imagination'. Clearly 'historical imagination' leaves space to be misinterpreted too; Seixas and Peck (2004) have offered 'historical perspective taking', but this, too, is a little cumbersome. It is doubtful that a suitably watertight single word actually exists for what Wineberg (2001) calls the 'unnatural act' of this kind of historical thinking.

However, what unites these ideas is a recognition that mentally inhabiting the past requires considerable historical knowledge and that a reciprocal relationship exists between that knowledge and the affective dimension of empathy. Historical empathy is not a skill that can be demonstrated, but a heuristic cycle in which imagination is informed by evidence, which in turn refines the imagination. Such reciprocity between the cognitive and affective domains is essential for the simple reason that our everyday imagination is a very poor guide to how people acted in the past. Historical empathy can help us comprehend the unfamiliar, but no amount of unschooled imagination can help us inhabit the mind of the witch hunter or comprehend the internal logic of trial by ordeal. Without careful consideration of context, we risk either bewilderment or condescension.

The presentation of 'empathy' in CfE contains none of this refinement. The word itself (or rather a derivative) is used on just one occasion in the Es and Os.

\begin{tabular}{|l|l|}
\hline Fourth & I can express an informed view about the changing nature of conflict over time, appreciate
\end{tabular} its impact and empathise with the experiences of those involved. SOc 4-06b 
The problem with this usage is readily apparent. Empathy is presented here as something students should do to understand the lives of people in extreme or emotionally challenging circumstances. Empathy in this conception ceases to be a component of historical thinking and becomes an exercise in understanding the afflicted. The danger, of course, is that this ceases even to be empathy in the loosest sense and veers into compassion or sympathy; Mitgefuhl over Einfuhlung. More prosaically, it would stand to reason that the more extreme the circumstances the less reliable is common empathy as a guide to how others felt. Recent historiography on the Great War demonstrates how soldiers were motivated to continue fighting by 'old-fashioned' notions of companionship, patriotism and a sense of duty (Holmes, 2005; Watson, 2009) which seem deliberately to resist our wellintentioned twenty-first century empathy. As Slater has argued, historical empathy may well have an important socialising function, 'empathetic thinking may also, may it not, make us less likely to patronise our fellow human beings? It might, just, sometimes help us choke back mockery, give condemnation second thoughts... put a brake on violence, and if not in others, at least in ourselves' (1989, p. 8). However, this socialising effect that Slater describes is perhaps better termed 'humility' rather than empathy. By seeing the past from the perspective of the past, children can avoid the arrogance of hindsight, the lures of presentism and the 'condescension of posterity' (Thompson, 1963). This is empathetic understanding, to be sure, but only in the loosest sense associated with Maitland that 'we should always be aware that what now lies in the past once lay in the future'. Slater values the transformative potential of empathy conceived thus, but he is emphatic that 'this is not the same as identifying with people in the past' (p. 7).

Interestingly, a more accurate representation of what historians mean by empathy is to be found at a lower level, albeit in a slightly different 'strand'.

\begin{tabular}{|l|l|}
\hline Third & I can discuss the motives of those involved in a significant turning point in the past and
\end{tabular} assess the consequences it had then and since. SOC 3-06a

This is an approach to empathy which Furlong (1961) describes as 'supposal', as opposed to 'imaging in '. At this level, historical empathy properly understood is a necessity; the child must understand the context of the decision as well as the factors binding the choice of actions for the person involved. There is a further dimension in which 'empathy' is important, since there is a need to comprehend how consequences have been perceived in the years since. The pupil must empathise not just with the original decision taker, but also with the people affected later by the consequences of that decision. This is a challenging and historically rigorous outcome grounded in historical empathy, it is simply confusing that the word is used so recklessly at the supposedly more challenging SOC 4-06b.

\section{Epistemological Errors}

Epistemological errors are always the corollary of ontological ones, but it is often at the epistemic level that these errors are most obvious. To clarify the distinction: historical ontology must have as its starting point a belief that accounts can be more or less faithful to the past, historical epistemology provides the tools and approaches that historians use to discover this knowable past and to create accounts. The importance of evidence in supporting historical claims and a competent and ethical use of source material is obviously integral to the pursuit of history - sources are the raw materials with which historians work.

PPES seems to have an ambiguous relationship with 'evidence'. Its importance is recognised by its being the first 'strand' of outcomes (SOC 0-001a to SOC 4-01a). Similarly, the primacy of evidential understanding is restated in the notes appended to the progression framework which stress that 'this set of experiences and outcomes provides progression in the evaluation of sources and other historical 
evidences and can be used in conjunction with other outcomes'. However, this phrasing is, itself, troublesome for it seems not to appreciate the distinction between 'source' and 'evidence'. A 'source' is a relic or record of the past which takes on the status of 'evidence' once a historian uses it to support a claim. Hence the phrase 'sources and other historical evidences' contains a redundancy - there are no evidences that were not at one time sources.

Furthermore, the very words 'Experience and Outcome' invite a tick-box approach in which an experience can be 'had' or an outcome can be 'met'. Such an approach is wholly inappropriate to scaffolding the development in a child's historical understanding. For example, SOC 2-01a which is designed to be 'met' in at upper primary level reads, 'I can use primary and secondary sources selectively to research events in the past'. It hardly bears mentioning that this is nothing more than a one-sentence description of the historical method in its entirety. This is not an outcome that can be met, but a statement of competence which, if it can be measured at all, can be done so only qualitatively since the statement encompasses everything from a reductive 'source work activity' in the primary classroom to the production of a scholarly monograph in a university history faculty. Clearly, teachers will use their professional judgement to pitch lessons appropriately, but do we really want to create the impression that 'using primary and secondary sources selectively' is an experience that can be had and then moved on from? By relying on competencies to describe a qualitative attribute, the curriculum arrives at outcomes which are at once insultingly simplistic and unbelievably complex.

Curricula are, by their very nature, epistemic devices - they frame and delimit knowledge and ontological and epistemological carelessness at the heart of curriculum planning has real effects in the classroom. By creating its own definition of progression, it shapes the activities and assessments that teachers plan and that pupils undertake. The final section will look at how an ill-considered epistemic framing has pedagogical consequences.

\section{Pedagogical Errors}

To better understand the contradictions inherent in the progression framework, it is useful to turn to the three curriculum models advanced by A.V. Kelly (1999) and which Priestley and Humes (2010) deployed in their analysis of CfE. For Kelly, curriculum can function as either 'content', 'product' or 'process' - the first of these specifies material to be mastered, the second objectives to be met and the third the mode of enquiry. Hence, process model would equip students with the epistemic tools to discover the past (what we have called procedural knowledge) while a product model would specify outcomes to be met. However, the CfE progression model seems to cut across these in a way which betrays a lack of understanding rather than playful eclecticism. The disciplinary approach to history teaching is firmly in the 'process' tradition - it argues that the subject consists of procedural concepts in which children can be inducted and can develop. The progression framework seems at times amenable to this approach, for example, SOC1-01a to SOC 4-01a are notionally concerned with evidential understanding while SOC 1-04s to SOC 4-04 a/b demand understanding of historical diversity. Such an approach does not suggest that historical understanding can be measured in atomised reductionist terms, but that the idea of 'progression framework' is not inherently antithetical to a disciplinary approach to children's progression. However, the progression model lacks even this coherence. Consider the following extract from the progression document:

First - I can use evidence to recreate the story of a place or individual of local historical interest. (SOC 1-03a)

Second - I can investigate a Scottish historical theme to discover how past events or the actions of individuals or groups have shaped Scottish society. (SOC 2.03a) 
Third - I can explain why a group of people from beyond Scotland settled here in the past and discuss the impact they have had on the life and culture of Scotland. (SOC 3.03a)

There is simply no overarching logic to the three expectations which explains why each level represents progression from the previous one. While SOC 1-03a seems to expect narrative recall (which strictly speaking is not a historical concept anyway), SOC 2.03a visits Change and Continuity and Historical Significance. The inclusion of SOC 3.03a is even stranger since it represents not procedural knowledge, but substantive knowledge of the concept of migration. It is not even clear why SOC 3.03a is more challenging than SOC 2.03a, it is even more unclear how one can be considered to have 'built on' or progressed from the other. This is not an isolated example. CfE superficially eschews prescription of content, but at the fourth level, the Es and Os seem to do little else. Consequently, 4-06b and 4-06c are recognisably about conflict, while 4-04a is about inequality, 4-04b ideas and beliefs, 4-04c democracy, 4-05b industrialisation and so on. In this way a framework designed to indicate progression (an idea which ought really to be underpinned by a disciplinary conception of the subject), actually becomes a document for specifying content. The result is a document which sends strange signals about what it means 'to get better' at history.

It is apparent that substantive concepts are specified principally at the fourth level, while procedural concepts appear throughout the levels. The effect is to imply that procedural knowledge as a precursor to substantive knowledge, where the latter is conceived of as more challenging, perhaps more akin to 'proper history'. Given the scope and depth of research into children's understanding of the past (not least (Shemilt, 1983) (Lee \& Ashby, 2000) (Howson \& Shemilt, 2011)) this represents a serious lacuna in the planning for historical learning within CfE. As Priestly and Humes (2010) have argued, 'there is no mention at all of the insights of research into the curriculum, whether from a philosophical, sociological or psychological standpoint (p358).

The relatively low status accorded to procedural knowledge can be further gleaned from the narrow definitions applied. Consider the curriculum's explanation of children's development of chronology from the appendix to the Es\&Os:

Chronology skills are developed progressively in a variety of contexts. The main stages of progression within these skills would be: sequencing evidence; creating sequences and timelines; locating events in sequence and time; representing situations before and after. SOC 2-06a

Here chronology is defined purely as a sequencing exercise, the existence of a single timeline is assumed and the challenge for the student is to place events on the timeline. Such activities are clearly indispensable (Wood, 1995) and research has shown that children struggle with even these fundamentals (Blow, et al., 2012). However, a reliance on timelines is not a panacea; chronological understanding properly understood is much more than sequencing. Sequencing can be actively unhelpful for the way it reinforces the child's idea of the past a single narrative; rather than an interplay between short-term events and longer processes - if dates are all one needs, where does one place "growing importance of cotton" on a timeline of the Industrial Revolution? Similarly, the language of periodization is central to chronological understanding and is neglected here but is hugely confusing to children. At what point in their historical education are children to learn that "Stone Age," "Early Modern" and "Restoration" are not concrete concepts, but labels whose durations and definitions differ between historians? 
Even if one accepts that such a narrow definition of chronology is appropriate for the early stages of a child's education, there are very many examples in the progression framework of students at one level being asked to demonstrate an ability which they will not be taught until the next level. For example, SOC 2-02a reads 'I can interpret historical evidence from a range of periods to help build a picture of Scotland's heritage and my sense of chronology'. Yet, in terms of evidential understanding it is only at the third level (SOC 3-01a) that pupils 'can use my [their] knowledge of a historical period to interpret the evidence and present an informed view'. Thus both outcomes ask pupils to 'interpret evidence', but at level two this must be a range of periods, while pupils at level three are asked to interpret evidence in relation to one period. While it could well be argued that the two enquiries are qualitatively different (one asks for depth, the other breadth), each relies on similar competencies and so it is not possible for children to achieve at the second level unless they have demonstrated a competency expected at the third.

As stated earlier, this paper makes no claims to knowledge about current practice in schools, but assessment criteria have a direct impact on practice, and in doing so shape students' consciousness of what a subject entails. As Priestley (2013) warned: 'It has become increasingly clear since 2010 that assessment against Es \& Os will be major feature of teachers' work within CfE [there has been] a shift in emphasis, making clear that the Es \& Os are assessment standards' (p. 32). If, as I have argued here, there are serious concerns about the type of progression being outlined, then there will be concomitant concerns about the activities that teachers scaffold and the way that children's historical thinking develops.

\section{Conclusion}

There is a current fashion in public discourse to conclude that a document is 'unfit for purpose', however such a dismissal is inappropriate in this instance because CfE has no clear statement of the purpose of 'People, past events and societies'. Subjects in CfE justify their position by the extent to which they can contribute to the four capacities: helping children to become successful learners, effective contributors, confident individuals and responsible citizens. A study of the past undoubtedly has a role to play in achieving all of these; however, it is critical to reflect on the obvious question of what exactly that role should be.

It is frighteningly easy to put the past to use- the past is an endless repository of stories and examples which can inform confident individuals and responsible citizens, but can anyone put the past to use and do so in a way which is ethically and epistemologically honest? Perhaps at the root of the problem, is the characterisation of PPES as a 'social subject'. History is 'social' only insofar as it studies people and that societies are comprised of people. But this commonality with other social subjects is tenuous: most people in history differ from those in geography, modern studies or business by virtue of being dead. To ignore this simple fact - that actors in the past can no longer speak for themselves and that historians are sense-makers creating accounts from relics and records, is to ignore what makes studying the past such a unique disciplinary endeavour. That CfE does not appreciate the profundity of this simple fact can be seen in the very title of People, Past Events and Societies - why do 'events' and 'societies' justify adjectival modification whereas 'people' does not? The need to maintain consistency of naming across the social subjects is not sufficient justification, historians study people in the past and a very specific kind of epistemology is needed to do so. Once history is conceived as a social subject, it is perilously close to being reimagined as a socialising subject.

In Lee's famous phrase, "the reason for teaching history is not that it changes society, but it changes pupils; it changes what they see in the world and how they see it" (1991, p. 43 Emphasis in original). History can contribute to the four capacities: it helps humans to orientate themselves in time and so 
broadens their perspectives; by realising that other worlds were once possible and so opening the imagination to what worlds might be possible. However, before all else, history is a set of mental dispositions. It is a commitment to truth, it is a promise to view the past with understanding rather than condescension, it is a recognition that the human world is forever in flux and that injustice is upsetting but impermanent. These are the lessons that an epistemologically sound study of the past offers. Are these not, in themselves, a sufficient contribution to the four capacities?

\section{Bibliography}

Blow, F., Lee, P. \& Shemilt, D., 2012. Time and Chronology: conjoined twins or distant cousins?. Teaching History, Volume 147, pp. 26-35.

Collingwood, R., 1946. The Idea of History. Oxford: Oxford University Press.

Coltham, J. \& Fines, J., 1971. Educational Objectives for the Study of History. London: Historical Association.

Counsell, C., 2011. Disciplinary Knowledge for all, the secondary history curriculum and history teachers' achievement. The Curriculum Journal, 22(2), pp. 201-225.

Deuchar, S., 1989. The New History: A Critique. York: Campaign for Real Education.

Education Scotland, 2013. Social studies: Assessing progress and achievement in significant aspects of learning, Accessed 2nd May 2016:

http://www.educationscotland.gov.uk/learningandteaching/assessment/progressandachievement/s ignificantaspectsoflearning/curriculum/socialstudies/progress.asp.

Evans, R. J., 1999. In Defence of History. New York: W. W. Norton \& Co..

Fenwick, A., Minty, S. \& Priestley, M., 2013. Swimming against the tide: a case study of an integrated social studies department. The Curriculum Journal, 24(3), pp. 454-474.

Foster, S. \& Crawford, K., 2006. What shall we tell the Children?: International Perspectives on School History Textbooks. Greenwich: Information Age.

Furlong, E., 1961. Imagination. London: George Allen \& Unwin.

Gove, M., 2009. What is Education for?. Speech to the RSA, 30 June, pp.

http://conservativehome.blogs.com/files/090630-gove-speech-to-rsa.pdf Accessed 21st August 2014.

Henry, S., 2006. 'Bruce! You're history.' The place of History in the Scottish Curriculum. Teaching History, Volume 122, pp. 34-36.

Hillis, P., 2008. History Education. In: T. Bryce \& W. Humes, eds. Scottish Education - Third edition: Beyond Devolution. Edinburgh: Edinburgh University Press, pp. 496-501.

Hirsch, E., 1987. Cultural Literacy: What every American needs to know. Boston: Houghton Mifflin. Holmes, R., 2005. Tommy: The British Soldier on the Western Front. London: Harper Perennial. 
Howson, J. \& Shemilt, D., 2011. Frameworks of Knowlegdge: Dilemmas and Debates. In: I. Davies, ed. Debates in History Teaching. London: Routledge, pp. 73-83.

Jenkins, k., 1991. Rethinking History. Abingdon: Routledge.

Kedourie, H., 1988. The Errors and Evils of the New History. London: Centre for Policy Studies.

Kelly, A., 1990. The National Curriculum: a critical review. London: Paul Chapman.

Kelly, A., 1999. The curriculum: theory and practice. 4th ed. London: Sage.

Learning and Teaching Scotland, 2008. Curriculum for Excellence: Experiences and Outcomes, Accessed 2nd May 2016:

https://www.educationscotland.gov.uk/Images/all_experiences_outcomes_tcm4-539562.pdf.

Lee, P., 1991. Historical Knowledge and the National Curriculum. In: R. Aldrich, ed. History in the National Curriculum. London: Kogan Page, pp. 39-65.

Lee, P., 1992. History in Schools: Aims, purposes and approaches. A reply to John White. In: D. Shemilt, ed. The Aims of School History: The National Curriculum and Beyond. London: Institute of Education, pp. 20-34.

Lee, P. \& Ashby, R., 2000. Progression in Historical understanding among students aged 7-14. In: Knowing, Teaching nad Learning History. New York: New York University Press, pp. 199-222.

Lee, P. \& Shemilt, D., 2003. "A Scaffold, not a Cage". Teaching History.

Lévesque, S., 2008. Thinking Historically: Educating Students for the Twenty-First Century. Toronto: Toronto University Press.

Lowenthal, D., 1997. Possessed by the Past: The heritage crusade and the spoils of history. 1st ed. New York: Free Press.

McGonigle, J., 1999. An Integrated or Discrete Approach. In: P. Hillis, ed. History Education in Scotland. Edinburgh: John Donald, pp. 157-169.

McGovern, C., 2007. The New History Boys. In: R. Whelan, ed. The Corruption of the Curriculum. London: Civitas, pp. 58-85.

Munro, N., 2005. Peacock snub for London reforms. Times Educational Supplement (Scotland), 4 November, p. https://www.tes.com/article.aspx?storycode=2153642 [Accessed 1st November 2015].

Nietszche, F., 1874. On the Use and Abuse of History for Life. In: T. b. A. Collins, ed. Wikisource. Downloaded as pdf 15/1/15: s.n., p.

http://en.wikisource.org/wiki/On_the_Use_and_Abuse_of_History_for_Life.

Ormond, B., 2011. Shifts in Knowledge Teaching: The unexpected consequences of assessment practices on secondary history. Pacific-Asian Education, 23(1), pp. 5-22.

Partington, G., 1986. History: Re-written in an ideological fashion. In: K. Dennis, ed. The Wayward Curriculum: A cause for Parents' Concern?. London: Social Affairs Unit.

Phillips, R., 1998. History Teaching, Nationhood and the State. London: Cassell. 
Potter, G. \& Lopez, J., 2001. After Postmodernism: The New Millennium. In: After Postmodernism: An Introduction to Critical Realism. London: Continuum, pp. 1-19.

Priestley, M., 2009. Social Studies in Scotland's school curriculum: a case for a more integrated approach. Education in the North, Volume 17.

Priestley, M., 2013. The 3-18 Curriculum in Scottish Education. In: T. Bryce, W. Humes, D. Gillies \& A. Kennedy, eds. Scottish Education - Fourth Edition: Referendum. Edinburgh: Edinburgh University Press, pp. 28-38.

Priestley, M. \& Humes, W., 2010. The development of Scotland's Curriculum for Excellence: amnesia and de ja vu. Oxford Review of Education, 36(3), pp. 345-361.

Schools' History Project, 1976. A New Look at History. Edinburgh: Homes MacDougall.

Scottish Executive, 2004. A curriculum for excellence - The curriculum review group. Edinburgh: s.n.

Scottish Government, 2006a. Education Scotland: Progress and Proposals. [Accessed 11th September 2015] ed. Edinburgh: http://www.gov.scot/resource/doc/98764/0023924.pdf.

Scottish Government, 2006b. Building the Curriculum 1. [Accessed 11th September 2015] ed. Edinburgh: http://www.educationscotland.gov.uk/Images/building_curriculum1_tcm4-383389.pdf.

Scottish Government, 2008. Building the Curriculum 3. Edinburgh: Scottish Government.

Seixas, P. \& Morton, T., 2013. Six Big Historical Thinking Concepts. Toronto: Nelson.

Seixas, P. \& Peck, C., 2004. Teaching Historical Thinking. In: A. Sears \& W. I, eds. Challenges and Prospects for Canadian Social Studies. Vancouver: Pacific Educational Press, pp. 109-17.

Shemilt, D., 1983. The Devil's Locomotive. History and Theory, XXII(4), pp. 1-18.

Shemilt, D., 2000. The Caliph's Coin. In: Knowing, Teaching and Learning History. New York: University Press, pp. 83-101.

Slater, J., 1989. The politics of history teaching: a humanity dehumanised?. London: Institute of Education.

Slater, J., 1992b. Where there is dogma, let us sow doubt. In: D. Shemilt, ed. The Aims of School History: The National Curriculum and Beyond. London: The Tufnell Press, pp. 45-54.

Smith, J., 2015. Community and Contestation: a critical discourse analysis of English history teachers' responses to the 2013 draft National Curriculum for History. Keele University Library: Unpublished EdD thesis.

SOED, 1993. National Guidelines: environmental studies 5-14. Edinburgh: Scottish Office Education Department.

Stengl, B., 1997. 'Academic Discipline' and 'school subject': Contestable curricular concepts. Journal of Curriculum Studies, 29(5), pp. 585-602.

Stenhouse, L., 1975. An introductionto curriculum research and development. London: Heinemann. Taylor, T. \& Guyver, R., 2011. History Wars and the Classroom: Global Perspectives. Charlotte: Information Age.

Thompson, E. P., 1963. The Making of the English Working Class. London: Victor Gollancz. 
Trevor-Roper, H., 1983. The HIghland Tradition. In: E. Hobsbawm \& T. Ranger, eds. The Invention of Tradition. Cambridge: Cambridge University Press, pp. 15-42.

Trevor-Roper, H., 2008. The Invention of Scotland: Myth and History. Cambridge: Cambridge University Press.

Watson, A., 2009. Enduring the Great War: Combat, Morale and Collapse in the German and British Armies 1914-18. Cambridge: Cambridge University Press.

White, J., 1992. The Purpose of School History: Has the National Curriculum got it right?. In: D. Shemilt, ed. The aims of school History: The National Curriculum and Beyond. London: Tufnell Press, pp. 9-20.

Wineberg, S., 2001. Historical Thinking and other unnatural acts: Charting the future of the teaching of the past. 1st ed. Philadelphia: Temple University Press.

Wood, S., 1995. Developing an understanding of time- sequencing issues. Teaching History, Volume 79, pp. 11-14..

Young, M., 2008a. Bringing Knowledge back in: From Social Constructivism to Social Realism in the Sociology of Education.. London: Routledge.

Young, M., 2008b. From Constructivism to Realism in the Sociology of the Curriculum. Review of Research in Education, Volume 32, pp. 1-28.

Young, M. \& Muller, J., 2010. Three educational scenarios for the future: Lessons from the sociology of knowledge. European Journal of Education, 45(1), p. 12-27.. 